\title{
O DIREITO DE EXPLORAR E O DIREITO DE VIVER
}

SAKAMOTO, Leonardo (org.). Escravidão contemporânea. São Paulo:

Contexto, 2020. 191p.

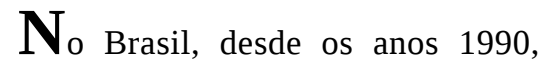
nos acostumamos a ver na TV, nos jornais e posteriormente na internet, notícias de trabalhadores encontrados pelo Estado em condições de extrema exploração, que incluem alojamentos compartilhados com animais e seus excrementos, insuficiência de alimentação, jornadas incompatíveis com a resistência do corpo humano, dentre outras situações que chocam qualquer observador minimamente empático. Inicialmente, esses fatos pareciam circunscritos a locais distantes e de difícil acesso, particularmente em zonas rurais e no norte do país. Com o passar do tempo, começamos a assistir esses episódios nas grandes cidades e nos mais diferentes setores econômicos.
A palavra escravo invariavelmente aparece associada a esses flagrantes, e ela é o fio condutor que ajuda a chamar a atenção para as formas extremas de exploração do trabalho, mas ao mesmo tempo é utilizada por aqueles que lucram com esse padrão predatório de gestão para tentar minimizar as situações encontradas (afinal, dizem os empregadores, "os trabalhadores não estavam presos”). Mesmo a grande mídia corporativa, defensora contumaz da destruição do direito do trabalho, costuma dar espaço aos resgates de trabalhadores e sempre adota um tom de reprovação às situações flagradas. Ademais, todos os atores envolvidos, inclusive empresas ou seus prepostos, negam enfaticamente qualquer relação com o trabalho escravo e dizem condená-lo. Por que, então, persistem a 
polêmica sobre a própria definição do tema e, mais importante, as condições desumanas a que são submetidos trabalhadores ao redor do mundo?

O livro Escravidão contemporânea, organizado pelo jornalista, professor e militante dos direitos humanos Leonardo Sakamoto, nos traz pistas sobre esse problema que atormenta as forças civilizatórias em nosso planeta. O foco principal da obra é o Brasil, mas há capítulos com abordagens mais gerais, abarcando diversos países e a própria dinâmica do planeta Terra enquanto ecossistema. Sem dúvida, o livro é excelente, sendo leitura obrigatória especialmente para aqueles que querem se iniciar no tema.

Um dos grandes méritos da organização do livro foi conseguir reunir autores que são verdadeiros ícones nacionais e internacionais na luta contra as formas extremas de exploração do trabalho, como o padre e professor Ricardo Rezende, o frei Xavier Plassat e o professor Kevin Bales, além de agentes diretamente envolvidos na regulação do trabalho, como auditores fiscais, procuradores, e pesquisadores brasileiros e estrangeiros. O próprio organizador,
Sakamoto, por meio do seu trabalho na ONG Repórter Brasil e em veículos de comunicação, é um dos grandes responsáveis pelo destaque dado ao trabalho análogo ao escravo na mídia e na cena política brasileiras.

O livro é composto por nove capítulos, além da introdução, escrita por Sakamoto. Nesta constam alguns dos pontos que perpassam os demais textos da obra. "Todo ano, milhares de pessoas são traficadas e submetidas a condições desumanas de serviço e impedidas de romper a relação com o empregador. Não raro, são impedidas de se desligar do trabalho até concluírem a tarefa para a qual foram aliciadas, sob ameaças que vão de torturas psicológicas a espancamentos e assassinatos. No Brasil, essa forma de exploração é chamada de trabalho escravo contemporâneo. [...] A partir de 13 de maio de 1888, por meio da Lei Áurea, o Estado brasileiro deixou de reconhecer $\mathrm{o}$ direito de propriedade de uma pessoa sobre outra. Contudo, persistiram estratégias de submissão dos trabalhadores, as quais, a despeito de não terem respaldo oficial, negavam a eles liberdade e, sobretudo, dignidade" (p. 8, grifos meus). 
No primeiro capítulo, "Histórias de liberdade", o auditor fiscal do trabalho André Roston, ex-coordenador do grupo móvel de fiscalização do governo federal, relata uma série de episódios de resgates de trabalhadores, fornecendo um rico panorama das condições normalmente encontradas pelos agentes do Estado, dos procedimentos adotados, dos desafios à regulação e das repercussões das ações. Destaco sua impressão positiva sobre a efetividade das fiscalizações, em que pesem as limitações da atuação estatal para evitar o crime: "apesar dos seguidos flagrantes, acolhimentos e responsabilizações, não é possível dizer que a vulnerabilidade dos trabalhadores tenha mudado radicalmente apenas em razão dos resgates. O Estado brasileiro não amadureceu ainda suas políticas públicas a ponto de garantir que cada indivíduo vitimado tenha todas as condições de se livrar do círculo vicioso do trabalho escravo contemporâneo. Mas as práticas abusivas de contratação e exploração utilizadas nos setores e regiões fiscalizados sucessivamente passam a não ser tão vantajosas e vão sendo progressiva e teimosamente alteradas” (p. 27).
Como o perfil das ações de combate ao trabalho análogo ao escravo é geralmente muito menos condescendente com os infratores do que o padrão da atuação das instituições de regulação do direito do trabalho, é plausível perceber uma maior efetividade desse foco de atuação, ainda que limitada. ${ }^{1}$

Em seguida, em "A história da proibição da escravidão”, Mike Dottridge, ex-diretor da Anti-Slavery International e da Anistia Internacional, discute o papel dos diplomas internacionais criados para eliminar a escravidão, o trabalho forçado, a servidão e o tráfico de pessoas, problematizando a alegada redundância entre esses instrumentos jurídicos. Ele argumenta que, pelo contrário, os diplomas colaboram para "impor obrigações bem mais amplas aos Estados para prevenir escravidão, práticas análogas à escravidão, servidão, trabalho forçado e tráfico de pessoas, bem como para proteger todas as pessoas dessas formas de abuso e violência, particularmente pela adoção

\footnotetext{
1 Ver Vitor A. Filgueiras, "Estado e direito do trabalho no Brasil: regulação do emprego entre 1988 e 2008” (Tese de doutorado, Universidade Federal da Bahia, 2012).
} 
e implantação de um arcabouço jurídico adequado" (p. 49).

No terceiro capítulo, "O trabalho escravo após a Lei Áurea”, Ricardo Rezende discute como o fim da legalidade da escravidão no Brasil não foi capaz de impedir que trabalhadores continuassem submetidos a formas extremas de exploração, que ele e os demais autores identificam como escravidão contemporânea (ou simplesmente escravidão), com foco em processos chaves de promoção desse fenômeno na Amazônia, como o ciclo da borracha e o papel da SUDAM. Por fim, destaca como o combate ao trabalho análogo ao escravo no Brasil tem vivido avanços e retrocessos, estes últimos evidentes atualmente com a chamada reforma trabalhista.

No quarto capítulo, "Como o Brasil enfrenta o trabalho escravo contemporâneo", o ex-coordenador de combate ao trabalho escravo do Ministério Público do Trabalho, Tiago Muniz Cavalcanti, analisa o conceito de escravidão e apresenta as políticas empregadas para combatê-la no nosso país, particularmente em seu aspecto repressivo. É um ótimo apanhando das medidas existentes para conhecimento de leitores não iniciados no tema. Quanto ao debate conceitual sobre escravidão, após criticar os estereótipos existentes sobre o problema, o autor aborda a expressão tipificada no código penal brasileiro, trabalho análogo ao escravo (artigo 149), argumentando que ela "carrega consigo certo grau de eufemismo na designação de situações que rompem os padrões mínimos de civilidade e sociabilidade. A referência a "condições análogas" sugere uma conotação de abrandamento da conduta ilícita, odiosa em si. Parece designar situações que apesar de semelhantes - são distintas da escravidão” (p. 72).

De fato, o termo “escravo” é mais eficiente para a sensibilização imediata de um interlocutor que seja confrontado com uma situação de exploração extrema do trabalho e desconheça o tema. Nesse sentido, a inserção da palavra "análogo" na definição do fenômeno pode não chocar tanto, dando certa razão ao argumento de Cavalcanti. Contudo, usar apenas o termo "escravo" para definir o problema (e o crime) cria o impasse que tem dificultado a regulação protetiva do trabalho nas últimas décadas, porque a 
natureza da coerção do trabalho no capitalismo contemporâneo é efetivamente distinta da escravidão, não estando ligada, em geral, a formas individuais e diretas de coerção (sejam físicas ou simbólicas) sobre as pessoas subordinadas. ${ }^{2}$ É com base nessa diferença que empresários e seus prepostos atacam o quadro jurídico brasileiro e dificultam a sua efetividade. Enfim, o apelo mais fácil que a palavra "escravo", usada isoladamente, engendra num primeiro momento se traduz em uma maior dificuldade para impor limites à exploração do trabalho de modo mais perene.

No capítulo 5 seguinte, "O perfil dos sobreviventes”, Natália Suzuki, doutoranda em Ciência Política pela Universidade de São Paulo, e Xavier Plassat, coordenador da área de combate à escravidão da Comissão Pastoral da Terra, apresentam características dos trabalhadores resgatados no Brasil, a partir dos dados do Seguro Desemprego e resultados das

2 Sobre esse debate fundamental, ver Vitor A. Filgueiras, "Trabalho análogo ao escravo e o limite da relação de emprego: natureza e disputa na regulação do Estado”, Brasiliana, n. 2 (2013), p. 187 ש.
Fiscalizações disponibilizados pela Secretaria de Inspeção do Trabalho. Por exemplo, dos resgatados até 2018, 31\% eram analfabetos e $39 \%$ não concluíram o quinto ano do ensino fundamental. Do total, 95\% dos trabalhadores eram homens, e $63 \%$ tinham entre 18 e 34 anos. O perfil racial não foi registrado. Os locais de origem mais frequentes dos trabalhadores eram Maranhão, Bahia, Minas Gerais e Pará. Trata-se de um mapeamento muito importante, mas que precisa ser analisado com cautela porque os dados são referentes apenas aos resultados das fiscalizações, portanto, constituem uma amostra enviesada por todas as limitações inerentes à operação da instituição. Para ilustrar, apenas na primeira década dos anos 2000 ações em áreas urbanas se tornaram comuns, o que não quer dizer que antes não houvesse episódios de trabalho análogo ao escravo nas cidades.

Na sequência, capítulo 6, “Como o mundo enfrenta o trabalho escravo contemporâneo”, Renato Bignami, auditor fiscal do trabalho, discute os instrumentos de combate às formas extremas de exploração em 
uma série de países, como Reino Unido, França, Austrália e Estados Unidos. Segundo o autor, o texto apresenta "brevemente a intensidade e diversidade de formas pelas quais o trabalho escravo contemporâneo se expressa ao redor do mundo e como os Estados vêm desenvolvendo políticas e mecanismos de enfrentamento aos ilícitos correlatos, a partir de algumas experiências nacionais que se destacam no cenário” (p. 109). Assim como na síntese de Cavalcanti para os instrumentos jurídicos existentes no Brasil, Bignami faz um bom apanhado das ferramentas disponíveis nos países selecionados, constituindo um bom ponto de partida para o leitor que desconhece o mundo do trabalho desses locais.

Bignami conclui o capítulo com considerações importantes, particularmente quanto às dificuldades que o enfretamento do que chama de "trabalho escravo contemporâneo" sofre pelas características da atual conjuntura capitalista, de exaltação do livre mercado, financeirização, terceirização e força do direito empresarial.

Em seguida, o capítulo 7, “Trabalho escravo contemporâneo: um negócio lucrativo e global”, escrito por Siobhán McGrath, professora da Universidade de Durham, na Inglaterra, e Fabiola Mieres, pesquisadora da mesma instituição, as autoras discutem a relação entre a falta de liberdade nas relações trabalhistas e as chamadas cadeias produtivas, além de analisar a experiência brasileira de combate ao trabalho análogo ao escravo. Elas destacam a responsabilização que as leis brasileiras impunham (antes da ampla liberalização da terceirização efetuada pela reforma trabalhista) às empresas contratantes (“líderes", na terminologia das autoras) de outras empresas pelas condições a que estas submetiam seus trabalhadores subcontratados. Para as autoras, a "regulação para manter e/ou expandir o cumprimento [ou a efetivação da legislação] é chave. Empresas foram responsabilizadas por condições de trabalho dentro de suas cadeias produtivas, já que as companhias foram impedidas legalmente de terceirizar sua atividade-fim. $\mathrm{O}$ fato de que isso se encontra sob ataque por meio de reformas legais implica sérios problemas” (p. 147).

No capítulo 8, “O impacto da escravidão nas mudanças climáticas”, Kevin Bales, da Universidade de Nottingham, na Inglaterra, 
coautor do Índice de Escravidão Global e fundador da ONG Free the Slaves, discute a relação entre trabalho escravo e destruição da natureza. Segundo o autor, "nos últimos séculos, as atividades humanas causaram tanto impacto ao planeta Terra a ponto de se tornarem uma força geológica significativa, influenciando de forma profunda diversos elementos do meio ambiente. As mudanças climáticas são um dos aspectos mais relevantes dessas transformações, e o aumento de sua intensidade deve atingir as populações mais vulneráveis ao redor do globo (além de colocar mais seres humanos nessa categoria)" (p. 151). Seu argumento principal é: "O que tem acontecido, e ainda acontece no mundo inteiro todos os dias, é um ciclo de escravidão e destruição ambiental que segue sem cessar, destruindo tanto o mundo natural quanto as vidas das pessoas escravizadas e forçadas a levar a cabo a destruição desse ambiente natural” (pp. 156-157).

A ideia de um círculo vicioso em que destruição da natureza e escravidão se retroalimentam é plausível, todavia, precisa ter pensada com bastante cautela. De fato, a destruição ambiental contribui para tornar vulneráveis populações que experimentam a eliminação de suas formas alternativas de vida (portanto, estimula formas extremas de exploração). Por outro lado, na história do capitalismo, muitas das atividades econômicas em que os trabalhadores conseguiram obter condições mais protegidas de trabalho são, da mesma forma, altamente prejudiciais ao meio ambiente.

A recíproca da retroalimentação parece ainda mais complicada. Se é plausível que trabalhadores em condições de extrema exploração são muitas vezes utilizados para atividades destrutivas, como o desflorestamento, nada garante que padrões menos espoliativos de gestão do trabalho destruirão menos a natureza. Pelo contrário, uma organização do trabalho mais civilizada, empregando tecnologia de ponta, pode ser muito mais eficiente na destruição da natureza. Por outro lado, é possível que a tecnologia seja empregada para degradar menos a natureza, mas explorar (ou continuar explorando) ao extremo os trabalhadores, como no caso da substituição das queimadas e do corte manual de cana pelo uso de 
grandes máquinas operadas por trabalhadores em jornadas extenuantes, que se associam ao aumento dos acidentes fatais no setor. ${ }^{3}$

Em suma, é o capital que destrói a natureza e explora o trabalho, e destruir ou explorar menos depende estritamente da imposição de regulação exógena à lógica compulsiva do lucro. E nada garante que imposição de limites ao capital vai beneficiar simultaneamente natureza e trabalhadores. Em suma, a ideia da retroalimentação entre destruição ambiental e exploração do trabalho, como apresentada por Bales, tira o foco da relação social que destrói homens e natureza e coloca a ênfase na própria destruição, que aparece como fator causal.

O último capítulo do livro, na verdade um posfácio, "A herança do racismo", é provavelmente o mais interessante. Analisa a relação entre racismo, regionalismo e trabalho análogo ao escravo no Brasil. Escrito por Raissa Roussenq Alves, mestra em Direito pela Universidade de Brasília e ex-representante do Conselho Federal da Ordem dos Advogados do Brasil na

3 Ver Vitor Filgueiras, Saúde e segurança do trabalho no Brasil, Brasília: Movimento, 2017.
Comissão Nacional para a Erradicação do Trabalho Escravo, o artigo critica o fato de que, nos estudos sobre escravidão contemporânea "as hierarquias raciais entre proprietários e trabalhadores assumem um lugar periférico, optando-se por uma abordagem que privilegia a vulnerabilidade econômica como fator decisivo para a arregimentação de mão de obra escravizada. A assimilação da ideia de que as diferenças étnicas são pouco relevantes na escravidão atual tem como uma de suas consequências a quase inexistência de estatísticas e análises com enfoque na relação entre cor e trabalho em condições análogas às de escravo” (p. 181).

Do ponto de vista da oferta da força de trabalho, o papel do racismo como fator de promoção do trabalho análogo ao escravo é evidente e aparece em outros capítulos do livro. Por exemplo, Sakamoto afirma que “o trabalhador escravizado é pobre. E a pobreza, infelizmente, ainda persiste e tem 'preferência' por cor de pele no Brasil” (p. 9).

No que concerne à demanda por força de trabalho, ou seja, ao papel dos empregadores, o racismo opera de modo evidente no conjunto do 
mercado de trabalho. Como os negros são discriminados no processo de contratação, há uma restrição das opções de ocupação e eles tendem a ser alijados para a disputa dos postos mais precários.

A dúvida que merece uma investigação mais precisa, do ponto de vista do racismo enquanto fator causal do trabalho análogo ao escravo, é sobre sua incidência direta. Como dito antes, no conjunto do mercado de trabalho o racismo dificulta a contratação. Haveria um processo inverso na contratação para postos em condições análogas às de escravos? Os negros seriam priorizados? Ou os empresários não discriminam por aparência quando vão contratar sob condições extremas de exploração? Ou, ainda, pelo contrário, o racismo opera dificultando a contratação de negros até nessas posições (com base nos preconceitos mais toscos)?

Por fim, vale ressaltar algumas questões que perpassam vários capítulos do livro e são relevantes para entender o trabalho análogo ao escravo (ou o trabalho escravo contemporâneo, como preferem os autores do livro). Todos eles compartilham, corretamente, o consenso de que "o trabalho escravo contemporâneo não é resquício de modos de produção arcaicos que sobreviveram ao capitalismo. Trata-se de um instrumento utilizado por empreendimentos para potencializar seus processos de produção e expansão" (p. 10). Há também consenso de que não se trata de um problema decorrente de empregadores menos capitalizados ou restrito a áreas remotas. Em mais de um capítulo aparece a preocupação explícita acerca dos efeitos que as chamadas reformas trabalhistas podem provocar na expansão das formas extremas de exploração do trabalhador.

O livro, sem dúvida, tem vários méritos. Uma questão central da luta contra as formas extremas de exploração, contudo, a despeito de ser abordada em vários dos capítulos, não é bem desenvolvida, qual seja, a importância do conceito que define o fenômeno e de como as disputas sobre a regulação se assentam nele. Em alguns momentos, parece que se trata de uma questão semântica: "Existe um debate global para uniformizar conceitos e nomenclaturas que não deve se esgotar tão cedo, dado que o fenômeno assume características 
próprias nos diferentes países em que se manifesta, apropriando-se de formas locais da exploração do ser humano e reinventando-as”, escreve Sakamoto (p. 10).

Não por acaso, a liberdade, como variável relevante para explicar as formas extremas de exploração no capitalismo contemporâneo, aparece numerosas vezes, até mesmo como elemento a ser medido. Siobhán McGrath e Fabiola Mieres afirmam que, "no geral, há um crescente consenso acadêmico segundo o qual devemos nos atentar aos diferentes níveis de falta de liberdade que os trabalhadores vivenciam, dentro dos quais apenas os casos mais extremos se encaixam nos critérios particulares dessas categorias legais. Essa ideia ficou conhecida como abordagem do 'espectro' ou do continuum (outra pessoa)” (p. 132). O próprio Sakamoto acentua a liberdade (ou melhor, sua negação) como elemento relevante para o fenômeno atual: “as naturezas legal e econômica do trabalho escravo contemporâneo diferem das características do trabalho escravo da
Antiguidade clássica e daquela que aqui existiu durante a Colônia e o Império. Entretanto, o tratamento desumano, a restrição à liberdade e o processo de "coisificação" dos trabalhadores são similares” (p. 8, grifos meus). É por conta dessa perspectiva de análise que empregadores flagrados submetendo trabalhadores a condições análogas às de escravo repetem, de modo uníssono, que eles estavam lá voluntariamente e não havia qualquer restrição à liberdade de ninguém, o que encontra muitas vezes eco junto às instituições do Estado.

Entretanto, a liberdade, entendida sob a ótica das restrições ao direito de ir e vir (seja físico ou simbólico), não é o fator central que explica as formas extremas de exploração do trabalho no capitalismo contemporâneo. Enquanto atores e instituições que se mobilizam contra a exploração sem limites não superarem, consistentemente, a relação entre a subjugação do trabalho e a coerção individual direta (violência física, ameaça etc.), ou insistirem na condição de ser ou não livre, vamos sempre dar margem de manobra aos adversários e nos desviar do elemento 
essencial que submete os trabalhadores a essas condições: a coerção do mercado de trabalho baseada na eliminação do "direito de viver". ${ }^{4}$

Vitor Araújo Filgueiras (DD Universidade Federal da Bahia doi: 10.9771/aa.v0i61.39127
4 Na famosa definição do "moinho satânico” de Karl Polanyi, A grande transformação: as origens de nossa época, Rio de Janeiro: Campus, 2000. 